\title{
The distinctive short-term response of late-pregnant prolific ewes to propylene glycol or glycerol drenching
}

\author{
T. Alon, ${ }^{1,2}$ A. Rosov, ${ }^{1}$ L. Lifshitz, ${ }^{1}$ H. Dvir, ${ }^{1}$ E. Gootwine, ${ }^{1}$ and U. Moallem ${ }^{1 *}$ \\ ${ }^{1}$ Department of Ruminant Science, Institute of Animal Sciences, The Volcani Center, 68 HaMaccabim Road, Rishon LeZion 7505101, Israel \\ ${ }^{2}$ Department of Animal Science, the Robert H. Smith Faculty of Agriculture, Food and Environment, The Hebrew University of Jerusalem, \\ Rehovot 76100, Israel
}

\section{ABSTRACT}

Pregnancy toxemia is the most frequent metabolic disorder of ewes in late pregnancy. Although propylene glycol (PG) and glycerol (GLY) are common glucogenic supplements for treating pregnancy toxemia in ewes, the relative benefit of these 2 supplements is not entirely clear. Therefore, the objectives of the present study were to determine the changes during $24 \mathrm{~h}$ in key blood metabolites and insulin in response to PG or GLY drenching in prolific ewes. To this end, 36 multiparous late-pregnant Afec-Assaf ewes ( 132.4 d pregnant) bearing 2 to 4 fetuses, divided into 2 blocks (18 ewes in each block), with a blood $\beta$-hydroxybutyrate (BHB) concentration of 0.5 to $1.6 \mathrm{mmol} / \mathrm{L}$ were included. Ewes were divided into 3 groups (12 ewes each; 6 ewes in each experimental day), according to their BHB levels, expected litter size, body weight, and body condition score, and were drenched with the following: (1) control group (CTL), $55 \mathrm{~mL}$ of water; (2) PG, $106 \mathrm{~mL}$ of PG (100\% PG, 448 calories); or (3) GLY, $108 \mathrm{~mL}$ of Koforin 80 (80\% GL; 448 calories). Blood samples were taken before drenching and every hour after drenching for $24 \mathrm{~h}$. Plasma concentration of glucose, BHB, nonesterified fatty acids, lactate, glycerol, and insulin were determined. Because there were no effects of treatments after $12 \mathrm{~h}$ in the first block, the data were analyzed for $12 \mathrm{~h}$ after drenching rather than $24 \mathrm{~h}$. The plasma glucose concentration during the first $5 \mathrm{~h}$ after drenching was the highest in the GLY, BHB concentration was the lowest in the PG, and the nonesterified fatty acid levels were lower in the PG compared with the CTL ewes during the first $5 \mathrm{~h}$ after drenching. However, glucose concentration was higher in the PG ewes at 9, 11, and $12 \mathrm{~h}$ after drenching than in CTL or GLY ewes. The mean lactate concentration in plasma for $12 \mathrm{~h}$ was 2.5- and 1.9-fold higher in the PG compared with the

Received January 20, 2020.

Accepted June 17, 2020.

*Corresponding author: uzim@volcani.agri.gov.il
CTL and GLY ewes, respectively, and except at $11 \mathrm{~h}$ after drenching, it was significantly higher at each time point. The insulin concentration was higher in the GLY than in both other groups at 2 to $5 \mathrm{~h}$ after drenching. These results suggest that during the first few hours after drenching the effect of PG was more effective in reducing the BHB concentration, whereas the GLY effect was more effective in enhancing glucose concentration. The increased concentration in lactate following PG treatment suggests that the PG contribution to gluconeogenesis is mediated through its metabolism to lactate. In contrast, the lack of an effect on lactate, and the faster increase in blood glucose in response to GLY suggest that GLY has a more advanced entry point to gluconeogenesis, which influences the immediate response in enhancing the glucose blood concentration. Key words: propylene glycol, glycerol, pregnancy toxemia, prolific ewes

\section{INTRODUCTION}

Pregnancy toxemia (PT) is the most frequent metabolic disorder of ewes in late pregnancy when carrying more than 1 fetus (Sargison, 2007). Furthermore, it is a major cause of economic loss to the sheep industry (Scott et al., 1995). It has been estimated that the frequency of PT in Afec-Assaf ewes carrying 1 or 2 fetuses is only $0.5 \%$, whereas, in similar ewes carrying $\geq 3$ fetuses, it is as high as 19\% (Zamir et al., 2009). About $60 \%$ of fetal growth takes place in the last trimester of gestation (Twardock et al., 1973), when approximately 33 to $36 \%$ of the ewe's circulating glucose is directed to the fetoplacental unit (Hay et al., 1983). As the number of fetuses increases, the metabolic demands of the gravid uterus increase and thereby affect the profile of the maternal plasma metabolites. Improper nutritional management at late pregnancy in prolific sheep can lead to PT in the ewe and intrauterine growth restriction of the growing fetuses (Wu et al., 2006). Although nutrition appears to be the most critical factor affecting maternal and fetal metabolism in late-pregnant ewes, 
little information is currently available on the feeding requirements of highly prolific ewes carrying $\geq 3$ fetuses.

In our previous study (Moallem et al., 2012), we demonstrated a decrease in glucose and insulin blood concentration during the third trimester of pregnancy and an increase in the concentration of BHB and nonesterified fatty acids (NEFA) in ewes carrying 4 fetuses compared with ewes carrying only 1 fetus. These changes in metabolites and insulin concentration indicate fat mobilization to compensate for the high demand and the low supply of energy precursors. A greater NEFA supply stimulates hepatic oxidation of fatty acids and increases the hepatic export of ketone bodies (Drackley, 1999). Hypoglycemia and hyperketonemia are the main PT indicators in late-pregnant ewes. Thus, the main goal of PT treatment is to provide glucogenic precursors, which may increase plasma glucose, decrease lipolysis, and reduce BHB concentration (Herdt and Emery, 1992). Propylene glycol (1,2-propanediol; PG) and glycerol (1,2,3-propanetriol; GLY), which are considered as glucogenic precursors, are the most common treatments in use for ewes with $\mathrm{PT}$ symptoms. The use of PG is limited because of its toxicity in high dosage (Nielsen and Ingvartsen, 2004), whereas GLY is considered safer. Propylene glycol can affect the glucogenic status via 2 primary pathways. In the first, the PG ferments in the rumen, primarily into propionic acid, which converts in the liver mitochondria to succinyl$\mathrm{CoA}$ and integrates into the Krebs cycle (Nielsen and Ingvartsen, 2004). In the second pathway, the PG is absorbed intact and is metabolized in the liver to produce lactate; then it is converted to pyruvate and finally to oxaloacetate (OAA; Kristensen and Raun, 2007). In contrast, GLY can be absorbed intact into the bloodstream, where it reaches the liver and integrates into the cytosolic gluconeogenesis pathway, or partially converted to VFA in the rumen (Ferraro et al., 2009, 2016). Oxaloacetate plays an essential role in the production and regulation of energy in ruminants, and the lack of it is one of the reasons for the accumulation of ketone bodies in blood and urine during a metabolic depression (Cal-Pereyra et al., 2012).

The use of PG and GLY in livestock feeding has been common since the 1950s (Johnson, 1954). However, the relative benefits of these 2 supplements are not entirely clear, and there is no reliable information about the doses required to prevent or treat $\mathrm{PT}$ in ewes. We hypothesized that late-pregnant ewes treated with $\mathrm{PG}$ or GLY would demonstrate different blood glucose, BHB, NEFA, glycerol, lactate, and insulin concentration for $24 \mathrm{~h}$, because the absorbed substances and entry point to the relevant metabolic cycles may be diverse. To the best of our knowledge, the short- and long-term effects of these substances on key metabolite blood concentra- tion in prolific pregnant ewes, which are the most vulnerable population, were never examined. Therefore, the present study aimed to investigate the short-term response of late-pregnant prolific ewes bearing 2 to 4 lambs with elevated BHB concentration, and that were drenched with PG or GLY. We followed the diurnal changes of key metabolites, insulin, and enzymes in response to treatments.

\section{MATERIALS AND METHODS}

\section{Animals}

The Volcani Center Animal Care Committee approved all the procedures involving animals in the present study (approval no. 963/17 IL). This study was conducted on 36 multiparous Afec-Assaf ewes divided into 2 blocks, 18 ewes each, in the experimental flock at the Volcani Center, Rishon LeZion, Israel. The 2 blocks comprised different animals and were tested in different days. The prolific Afec-Assaf strain is considered as a dual-purpose breed and was developed by the introgression of the $B$ allele of the $F e c B$ (Booroola) locus to the Assaf breed (Gootwine et al., 2008). Reproduction management at the Volcani flock comprises 3 mating periods a year. Ewes included in the present study were hand mated following estrus synchronization, from mid-August through mid-September, and lambed from the following late January through mid-February (i.e., the winter season in Israel). The flock was kept in open sheds under nondairy management. All ewes were kept in 1 pen and group-fed ad libitum the same diet.

\section{Design and Treatment}

Pregnancy and the number of fetuses were determined on d 35 of gestation by transabdominal ultrasonography (3100v, Shenzhen Welld Medical Electronics Co. Ltd., Guangdong, China) in mated ewes, and 97 ewes in total bearing at least 2 fetuses were identified. Because the aim of this study was to examine the physiological but not necessarily the therapeutic effects of the supplements, we decided not to test the treatments on ewes with clinical PT symptoms. Therefore, $2 \mathrm{~d}$ before the experiment day, we took blood samples from the 97 pregnant ewes to determine the pretreatment $\mathrm{BHB}$ concentration. Blood samples were taken from the jugular vein using 1-mL syringes, and BHB concentration was determined (Freestyle optium, Abbott Diabetes Care, Alameda, CA). From those 97 ewes, 5 ewes showed clinical symptoms of PT and were excluded, and from the rest, 36 ewes with the highest blood BHB concentration were selected. The mean blood BHB concentration of the selected ewes was 7.2 
$\pm 2.8 \mathrm{mg} / \mathrm{dL}$, whereas the mean of those that were not included was $3.3 \pm 1.2 \mathrm{mg} / \mathrm{dL}$. We supposed that even though blood BHB concentration of the selected ewes was still within the normal range, these ewes are more prone to develop PT.

After selection, $2 \mathrm{~d}$ before the experiment day, the selected ewes of each block were weighed, and their BCS was determined (1-5 scale; Jefferies, 1961). One day before the experiment, ewes were locally anesthetized with $1 \mathrm{~mL}$ of lidocaine 2\% (Esracain 2\%; Rafa Laboratories, Jerusalem, Israel), and a jugular catheter (EQUIVET HiFlow 16G × 3.00, Jørgen Kruuse, Langeskov, Denmark) with a $20-\mathrm{cm}$ extension tube (KDL, Shanghai, China) was installed and fixed by stitching and applying an elastic bandage to the ewes' neck.

As aforementioned, the study was conducted in 2 blocks. In each block 18 ewes were stratified on the basis of blood BHB concentration, expected litter size, parity, BW, and BCS and then divided into 3 treatment groups: (1) control (CTL), in which ewes $(\mathrm{n}=12)$ were drenched with $55 \mathrm{~mL}$ of water; (2) PG, in which ewes $(\mathrm{n}=12)$ were drenched with $106 \mathrm{~mL}$ of propylene glycol (100\% PG; GADOT Chemicals, Haifa, Israel); and (3) GLY, in which ewes $(\mathrm{n}=12)$ were drenched with $108 \mathrm{~mL}$ of Koforin (containing 80\% glycerol, 15\% water, and 5\% ash; ADM, Hamburg, Germany). The supplements (PG and GLY) were balanced according to their specific molecular weight and energy content, taking into account that both supplements had similar energy contents per molecular weight. The ewes were orally drenched using $60-\mathrm{mL}$ disposable sterile plastic syringes once at $0700 \mathrm{~h}$ and were followed after drenching at the first block for $24 \mathrm{~h}$, and in the second block for $12 \mathrm{~h}$.

During the follow-up on each day, the ewes were fed at 1030 and $1430 \mathrm{~h}$ (i.e., $3.5 \mathrm{~h}$ and $7.5 \mathrm{~h}$ after drenching, respectively). Diet composition and content are presented in Table 1. The daily feed consumption was, on average, $1.95 \mathrm{~kg}$ of DM per ewe.

\section{Blood Sampling}

Blood samples were taken before drenching at $0630 \mathrm{~h}$ in the first block and at 0630 and $0645 \mathrm{~h}$ in the second block. The ewes were drenched at $0700 \mathrm{~h}$, and then blood samples were taken every hour for $24 \mathrm{~h}$ and $12 \mathrm{~h}$ in the first and the second blocks, respectively. Blood samples were taken from the jugular vein through the catheters into vacuum tubes containing lithium heparin (BD Vacutainer, Belliver Industrial Estate, Plymouth, UK) and immediately placed on ice. The plasma was separated by centrifugation for $15 \mathrm{~min}$ at $1,000 \times g$ at $4^{\circ} \mathrm{C}$, divided into 2 tubes, and stored at $-31^{\circ} \mathrm{C}$, pending analysis.
Table 1. Ingredients and chemical compositions of the ewes' diet

\begin{tabular}{lc}
\hline Item & Total \\
\hline Ingredient, \% of DM & \\
Corn, ground & 31.1 \\
Barley, rolled & 2.8 \\
Wheat grain, rolled & 1.6 \\
Rapeseed meal & 2.6 \\
Sunflower meal & 1.3 \\
Wheat bran & 4.6 \\
Wheat silage & 9.2 \\
Oat hay & 25.3 \\
Clover hay & 10.2 \\
Alfalfa cubes & 10.3 \\
Urea & 0.15 \\
Limestone & 0.8 \\
NaCl & 0.2 \\
Ammonium sulfate & 0.08 \\
Oil & 0.08 \\
Vitamins and minerals ${ }^{1}$ & 0.02 \\
Chemical composition & \\
ME, Mcal/kg of DM & 2.5 \\
CP, \% & 12.5 \\
NDF, \% & 42.2 \\
Forage NDF, \% & 25.5 \\
\hline
\end{tabular}

${ }^{1}$ Contained (per kg of DM) 20,000,000 IU of vitamin A; 2,000,000 IU of vitamin D; $15,000 \mathrm{IU}$ of vitamin E; $6,000 \mathrm{mg}$ of $\mathrm{Mn} ; 6,000 \mathrm{mg}$ of $\mathrm{Zn}$; 2,000 mg of Fe; 1,500 mg of Cu; $120 \mathrm{mg}$ of I; $50 \mathrm{mg}$ of Se; $20 \mathrm{mg}$ of Co.

At lambing, the number of lambs born and the number of those born alive were recorded. The birth weights of lambs were recorded within a few hours after lambing. Ewes' BW and BCS were recorded within 24 $\mathrm{h}$ after lambing. The gestation length for each ewe was calculated, based on the records of mating and lambing days. The data of ewes according to the 3 treatments are presented in Tables 2 and 3.

\section{Chemical Analysis}

Plasma concentration of glucose was determined using a Cobus C111 autoanalyzer (Roche Holding GmbH, Grenzach-Wyhlen, Germany), with the reagent set GLUC2, which used 2 enzymatic reactions with

Table 2. The data (mean \pm SD) of ewes at drenching day, according to the treatment groups

\begin{tabular}{lccc}
\hline & \multicolumn{3}{c}{ Treatment $^{1}$} \\
\cline { 2 - 4 } Variable & CTL & PG & GLY \\
\hline $\mathrm{n}$ Days in pregnancy, d & $131.3 \pm 8.3$ & $131.9 \pm 6.4$ & $134.1 \pm 4.8$ \\
Parity, n & $4.3 \pm 1.8$ & $3.9 \pm 1.6$ & $4.3 \pm 2.1$ \\
BW, kg & $107.5 \pm 12.3$ & $109.0 \pm 10.6$ & $106.3 \pm 14.3$ \\
BCS, unit & $3.0 \pm 0.3$ & $3.0 \pm 0.2$ & $3.0 \pm 0.3$ \\
Expected litter size, n & $2.3 \pm 0.5$ & $2.5 \pm 0.8$ & $2.5 \pm 0.8$ \\
BHB, mg/dL & $7.2 \pm 2.6$ & $7.3 \pm 3.2$ & $7.1 \pm 2.7$ \\
\hline
\end{tabular}

${ }^{1}$ High-prolific ewes were drenched once at $0700 \mathrm{~h}$; CTL $=$ control, 55 $\mathrm{mL}$ of water; $\mathrm{PG}=106 \mathrm{~mL}$ of propylene glycol; GLY $=108 \mathrm{~mL}$ of glycerol. 
hexokinase and glucose-6-phosphate dehydrogenase to generate a UV emission that was correlated with the sample glucose concentration; the results were calibrated against known glucose concentration.

Plasma BHB concentration was determined with a RANBUT D-3-Hydroxybutyrate kit (Randox, CruMLin, UK), in which a reaction of 3-hydroxybutyrate and dehydrogenase generates a UV emission correlated with the sample BHB concentration. The samples were examined at $340 \mathrm{~nm}$ with an optical density reader (spectro V-11D, MRC, Holon, Israel); the results were calibrated against known BHB concentration. The intra- and interassay coefficients of variation for the BHB assay were 1.3 and $1.8 \%$, respectively.

Plasma NEFA concentration was determined with a NEFA C Test Kit (Wako Chemicals GmbH, Neuss, Germany). The intra- and interassay coefficients of variation for the NEFA assay were 5.9 and $6.2 \%$, respectively.

Plasma lactate concentration was examined with a Cobus C111 autoanalyzer with the reagent set LACT2 (Roche Holding $\mathrm{GmbH}$ ), which used 2 enzymatic reactions with lactate oxidase and peroxidase to generate a UV emission that was correlated with the sample L-lactate concentration; the results were calibrated against known L-lactate concentration.

Triglyceride concentration was determined using a Cobus C111 autoanalyzer with the reagent TRIGL (Roche Holding $\mathrm{GmbH}$ ), which used 4 enzymatic reactions with lipase, glycerol kinase, glycerol phosphate oxidase, and peroxidase to generate a UV emission that was correlated with the sample triglyceride concentration; the results were calibrated against known triglyceride concentration.

Plasma insulin was determined by the insulin IRMA test kit (Beckman Coulter Inc., Fullerton, CA). The intra- and interassay coefficients of variation for the NEFA assay were 6.7 and $6.2 \%$, respectively.

Table 3. Data (mean $\pm \mathrm{SD}$ ) of dams and lambs at lambing, according to the treatment groups

\begin{tabular}{lccc}
\hline & \multicolumn{3}{c}{ Treatment $^{1}$} \\
\cline { 2 - 4 } Variable & CTL & PG & GLY \\
\hline Pregnancy length, d & $145.2 \pm 2.9$ & $144.8 \pm 1.8$ & $144.3 \pm 2.2$ \\
Ewe BW, kg & $88.0 \pm 12.6$ & $89.4 \pm 9.6$ & $89.5 \pm 13.8$ \\
Ewe BCS, unit & $2.4 \pm 0.6$ & $2.7 \pm 0.3$ & $2.7 \pm 0.4$ \\
Lambs born, n & $2.9 \pm 0.9$ & $3.0 \pm 0.9$ & $2.8 \pm 0.8$ \\
Lambs born alive, n & $2.0 \pm 1.0$ & $2.8 \pm 1.0$ & $2.4 \pm 0.8$ \\
Litter total weight, $\mathrm{kg}$ & $12.5 \pm 2.8$ & $13.0 \pm 2.0$ & $11.5 \pm 2.4$ \\
\hline
\end{tabular}

${ }^{1}$ Late-pregnant ewes were drenched once at $0700 \mathrm{~h}$; CTL $=$ control, $55 \mathrm{~mL}$ of water; $\mathrm{PG}=106 \mathrm{~mL}$ of propylene glycol; GLY $=108 \mathrm{~mL}$ of glycerol.
Plasma lactate dehydrogenase (LDH) catalytic activity was examined with a Cobus C111 autoanalyzer with the reagent set LDHI2 (Roche Holding GmbH), which used LDH to convert L-lactate to pyruvate; NAD is reduced to NADH in the process. The initial rate of the NADH formation is directly proportional to the catalytic LDH activity; a UV emission was generated that was correlated with the sample LDH catalytic activity; the results were calibrated against a known $\mathrm{LDH}$ activity standard.

Plasma aspartate aminotransferase (AST) catalytic activity was examined with a Cobus C111 autoanalyzer with the reagent set ASTL (Roche Holding GmbH), which used AST to convert L-aspartate and 2-oxoglutarate to oxaloacetate and L-glutamate. The oxaloacetate was then reacted with $\mathrm{NADH}$ in the presence of malate dehydrogenase to form $\mathrm{NAD}^{+}$. The rate of the NADH oxidation is directly proportional to the catalytic AST activity; it generates a UV emission that was correlated with the sample AST catalytic activity; the results were calibrated against a known AST activity standard.

\section{Statistical Analysis}

Because we did not observe effects of treatment for any parameter from 13 to $24 \mathrm{~h}$, we combined the data from both blocks and presented the results only for the first $12 \mathrm{~h}$ after drenching.

Plasma metabolites, insulin concentration, and enzyme activity were analyzed as repeated measurements using the PROC MIXED procedure, version 9.2 (SAS Institute Inc., Cary, NC). The model used was as follows:

$$
\begin{aligned}
& \mathrm{Y}_{\mathrm{ijkl}}=\mu+\mathrm{T}_{\mathrm{i}}+\mathrm{L}_{\mathrm{j}}+\mathrm{C}_{\mathrm{k}}+\mathrm{H}_{\mathrm{l}}+\mathrm{T}_{\mathrm{i}} \mathrm{H}_{1} \\
& +\mathrm{E}(\mathrm{T} \times \mathrm{C})_{\mathrm{ijklm}}+\mathrm{DIP}_{\mathrm{jklmn}}+E_{\mathrm{ijklmno}},
\end{aligned}
$$

where $\mu=$ the overall mean; $\mathrm{T}_{\mathrm{i}}=$ fixed effect of treatment, $\mathrm{i}=1$ to $3 ; \mathrm{L}_{\mathrm{j}}=$ fixed effect of dams' $\mathrm{BCS} ; \mathrm{C}_{\mathrm{k}}=$ fixed effect of block $=1$ or $2 ; \mathrm{H}_{1}=$ fixed effect of time (h); $\mathrm{T}_{\mathrm{i}} \mathrm{H}_{1}=$ interaction between treatment and time $(\mathrm{h}) ; \mathrm{E}(\mathrm{T} \times \mathrm{C})_{\mathrm{ijklm}}=$ ewe $\mathrm{m}$ nested in treatment and block; $\mathrm{DIP}_{\mathrm{ijklmn}}=$ the day in pregnancy as a continuous variable; and $E_{\mathrm{ijklmno}}=$ the random residual.

The effects of litter size, litter weight, and the dams' BW were tested and found to be not significant $(P$ $>0.05)$ for all variables that were tested; therefore, these factors were excluded from the final model. The interactions of treatment $x$ dams' BCS, treatment $x$ block, and treatment $\times$ day in pregnancy were tested and found to be not significant and therefore were not included in the final model. The autoregressive order 1 
was used as a covariance structure in the model because it resulted in the lowest Bayesian information criterion for most of the variables that were tested.

Data were tested for normality of distribution by the UNIVARIATE procedure of SAS and tested for homogeneity of variance by the Kolmogorov-Smirnov procedure. Because they were not normally distributed, data of BHB, NEFA, and lactate were $\log _{2}$ transformed before statistical analysis. The statistical analysis for BHB, NEFA, and lactate was performed on the transformed data, and the least squares means before transformation are presented in tables.

We analyzed the data for each sampling time (every hour) between groups with the GLM procedure, version 9.2 (SAS Institute Inc.). We also analyzed the treatment differences within each time point (every hour) using the model described above for multiple comparisons using the SLICE option. The Bonferroni adjustment was applied to decrease the probability of type I error when multiple treatment means were compared. Least squares means and adjusted standard error of the mean are presented in Table 4; $P<0.05$ was accepted as significant, and tendencies were stated at $0.05 \leq P$ $\leq 0.10$.

\section{RESULTS}

The study was conducted on late-pregnant AfecAssaf prolific ewes that averaged $107.6 \mathrm{~kg}$ of $\mathrm{BW}$ and lambed, on average, 2.9 offspring (Tables 2 and 3). No significant differences were observed between the 3 treatments regarding all lambing results. In the first block, we took blood samples every hour for $24 \mathrm{~h}$ after drenching, and found no differences between groups from 13 to $24 \mathrm{~h}$ after drenching in the main parameters that were tested $($ mean + SEM): glucose $=63.1 \pm 1.9$, 61.5, \pm 1.9 and $59.1 \pm 1.9 \mathrm{mg} / \mathrm{dL}(P=0.62)$; BHB
$=5.9 \pm 0.25,5.9 \pm 0.28$, and $5.2 \pm 0.28 \mathrm{mg} / \mathrm{dL}(P$ $=0.24) ; \mathrm{NEFA}=460 \pm 67,492 \pm 64$, and $630 \pm 65$ $\mu \mathrm{Eq} / \mathrm{L}(P=0.09) ;$ and insulin $=45.1 \pm 5.8,44.0 \pm$ 5.5 , and $47.9 \pm 5.6 \mu \mathrm{IU} / \mathrm{mL}(P=0.85)$ for the CTL, PG, and GLY groups, respectively. Therefore, in the second block, we followed the ewes only for $12 \mathrm{~h}$ after drenching. The results from both blocks together are presented for $12 \mathrm{~h}$ (Table 4). The results over time (12 h) for the blood metabolites and insulin concentration are presented in Figure 1.

\section{Plasma Glucose Concentration}

The analysis of the plasma glucose concentration for $12 \mathrm{~h}$ after drenching (Table 4) revealed no significant differences between treatments $(P=0.19)$. Plasma glucose concentration demonstrated a time effect $(P<$ 0.001 ), and the overall mean plasma glucose concentration increased over the $12 \mathrm{~h}$ of the study for all groups. An interaction between treatment and time for plasma glucose concentration was also detected $(P=0.001)$. The change in plasma glucose concentration over time are presented in Figure 1A. The mean basal glucose concentration for all ewes was $50.8 \pm 2.2 \mathrm{mg} / \mathrm{dL}$. The plasma glucose concentration for the GLY-treated ewes was greater when compared with the plasma glucose concentration of the CTL and PG groups at 1, 2, 3, 4 , and $5 \mathrm{~h}$ after drenching $(P<0.05)$. In addition, at $3 \mathrm{~h}$, it was $\sim 34 \%$ greater in the GLY-treated ewes compared with the CTL and PG-treated ewes (64.5 \pm $2.2,48.3 \pm 2.2$ and $48.2 \pm 2.2 \mathrm{mg} / \mathrm{dL}$, respectively; $P$ $<0.001)$. There was no difference in plasma glucose concentration between the GLY-treated ewes and the CTL ewes from 6 to $12 \mathrm{~h}(P>0.05)$. The plasma glucose concentration for the PG group was significantly greater than the other groups at 9,11 , and $12 \mathrm{~h}$ after drenching $(P=0.04)$.

Table 4. Mean ( \pm SEM) plasma metabolites and insulin concentration for ewes in 3 treatment groups

\begin{tabular}{|c|c|c|c|c|c|c|c|}
\hline \multirow[b]{2}{*}{ Item } & \multicolumn{3}{|c|}{ Treatment $^{1}$} & \multirow[b]{2}{*}{ SEM } & \multicolumn{3}{|c|}{$P$-value } \\
\hline & CTL & $P G$ & GLY & & Treatment & Time & Treatment $\times$ time \\
\hline $\mathrm{NEFA},{ }^{2} \mu \mathrm{Eq} / \mathrm{L}$ & $671.7^{\mathrm{a}}$ & $401.5^{\mathrm{b}}$ & $439.4^{\mathrm{b}}$ & 65.7 & 0.003 & $<0.001$ & 0.003 \\
\hline Lactate, $\mathrm{mmol} / \mathrm{L}$ & $0.6^{\mathrm{b}}$ & $1.5^{\mathrm{a}}$ & $0.8^{\mathrm{b}}$ & 0.08 & $<0.001$ & $<0.001$ & 0.66 \\
\hline $\mathrm{TG},{ }^{3} \mathrm{mg} / \mathrm{dL}$ & $21.5^{\mathrm{b}}$ & $32.3^{\mathrm{b}}$ & $73.1^{\mathrm{a}}$ & 12.1 & 0.01 & $<0.001$ & $<0.001$ \\
\hline AST, U/L & 70.7 & 63.5 & 62.3 & 3.1 & 0.15 & 0.68 & 0.40 \\
\hline
\end{tabular}

\footnotetext{
${ }^{\mathrm{a}-\mathrm{c}}$ Means within a row with different superscripts differ $(P<0.05)$.

${ }^{1}$ Late-pregnant ewes were drenched once at $0700 \mathrm{~h} ; \mathrm{CTL}=$ control, $55 \mathrm{~mL}$ of water; PG $=106 \mathrm{~mL}$ of propylene glycol; GLY $=108 \mathrm{~mL}$ of glycerol.

${ }^{2} \mathrm{NEFA}=$ nonesterified fatty acids.

${ }^{3} \mathrm{TG}=$ total glycerol.
} 

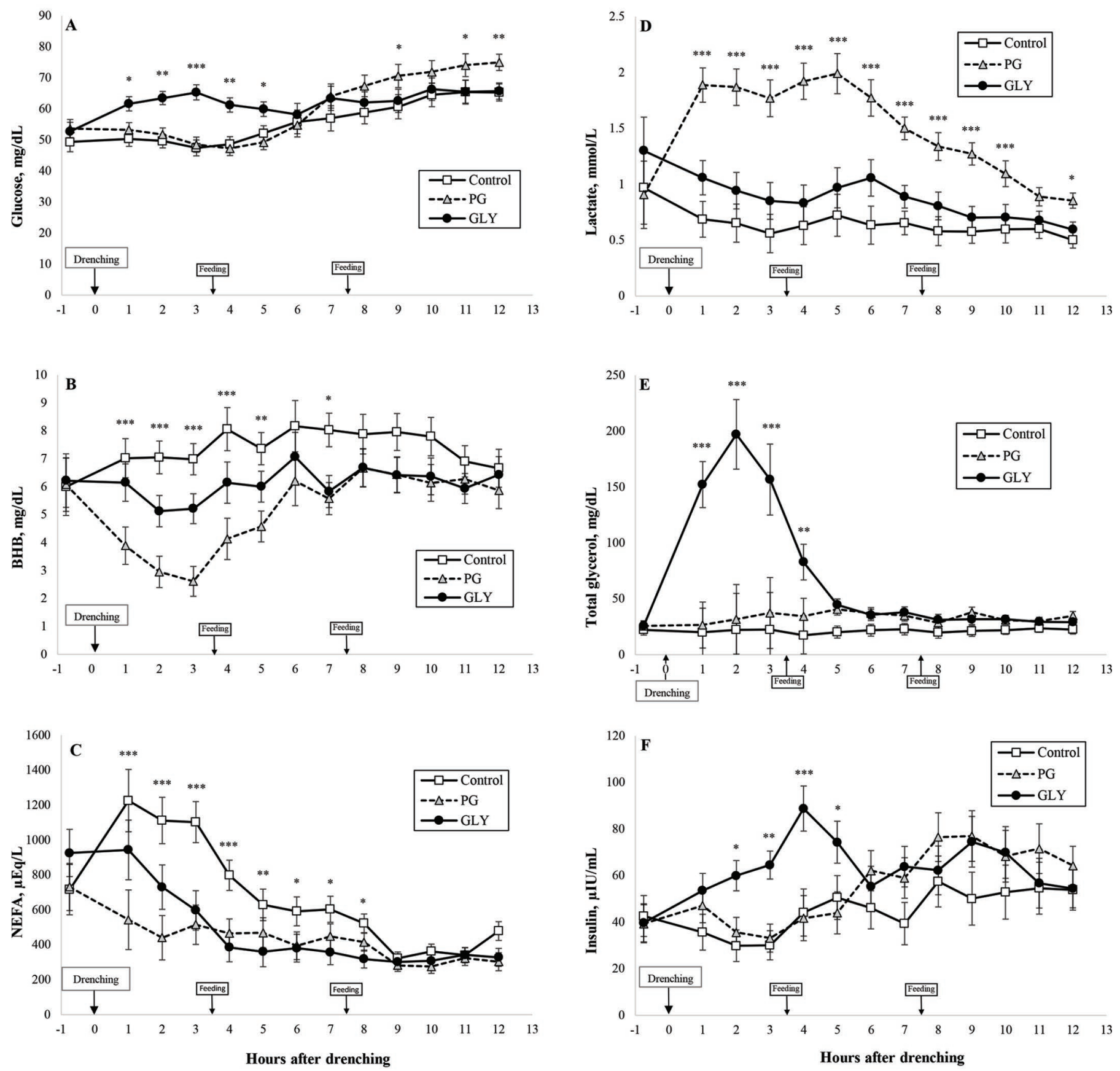

Figure 1. Plasma concentration of glucose (A), BHB (B), nonesterified fatty acids (NEFA; C), lactate (D), total glycerol (E), and insulin (F) from $30 \mathrm{~min}$ before and $12 \mathrm{~h}$ after drenching of late-pregnancy prolific ewes administered $55 \mathrm{~mL}$ of water (control), $106 \mathrm{~mL}$ of propylene glycol $(\mathrm{PG})$, or $108 \mathrm{~mL}$ of glycerol (GLY). The black arrows indicate the drenching time $(0 \mathrm{~h})$ and feeding times $(3.5$ and $7.5 \mathrm{~h}$ after drenching). $* * * P$ $<0.001,{ }^{* *} P<0.01,{ }^{*} P<0.05$. The error bars represent \pm SEM.

\section{Plasma BHB Concentration}

The overall mean plasma BHB concentration from the PG-treated ewes was $31.1 \%$ less when compared with the mean plasma BHB concentration from the CTL ewes $(P<0.001)$ and $17.7 \%$ less than the BHB concen- tration recorded for the GLY ewes $(P=0.007$; Table 4). A time effect $(P<0.001)$ and a treatment $\times$ time effect $(P<0.001)$ were also demonstrated. The changes in plasma $\mathrm{BHB}$ concentration over time are presented in Figure 1B. The basal plasma BHB concentration for all ewes was $6.3 \pm 0.65 \mathrm{mg} / \mathrm{dL}$. The PG-treated ewes 
demonstrated lesser plasma BHB concentrations at 1 , $2,3,4$, and $5 \mathrm{~h}$ compared with the CTL $(P=0.002)$ and GLY-treated $(P=0.04)$ ewes. The PG- and GLYtreated ewes had similar plasma BHB concentrations from 6 to $12 \mathrm{~h}(P=1.00)$. The CTL ewes demonstrated greater plasma $\mathrm{BHB}$ concentrations than the $\mathrm{PG}(P=$ $0.03)$ and tended to be greater than the GLY-treated ewes at $7 \mathrm{~h}(P=0.10)$ but were not different as compared with the PG and GLY groups at 6, 8, 9, 10, 11, and $12 \mathrm{~h}$ after drenching.

\section{Plasma NEFA Concentration}

There was an overall treatment effect $(P=0.003)$ and an overall time effect $(P<0.001)$ for NEFA concentration, such that the mean NEFA concentration in the PG ewes was $40 \%$ less $(P=0.002)$ and the GLY ewes $34.6 \%$ less $(P=0.004)$ when compared with the plasma NEFA concentration of the CTL ewes. There was no difference between the overall mean NEFA concentration of the PG and GLY groups $(P=0.79)$. An interaction of treatment and time for NEFA concentration was detected during $12 \mathrm{~h}$ after drenching $(P=0.003)$. The changes with time in plasma NEFA concentration are presented in Figure 1C. The mean plasma NEFA concentration $2 \mathrm{~h}$ after drenching was 2.5-fold less for the PG group compared with the CTL ewes $(440.8 \pm 127$ and $1,112 \pm 133 \mu \mathrm{Eq} / \mathrm{L}$, respectively; $P=0.001)$. Also, $2 \mathrm{~h}$ after drenching, the mean plasma NEFA concentration of the PG-treated ewes tended to be less $(39.7 \%$; $P$ $=0.06)$ compared with the NEFA concentration of the GLY-treated ewes. The NEFA concentration from $2 \mathrm{~h}$ after drenching until the end of the study was similar in both treated groups and was significantly less in the PG than the in the CTL ewes at $1,2,3,4 \mathrm{~h}(P<0.02)$ and less in the GLY than in the CTL ewes at 3, 4, 5, 7, $8 \mathrm{~h}$ after drenching $(P<0.02)$.

\section{Plasma Lactate Concentration}

There were overall treatment $(P<0.001)$ and time $(P<0.001)$ effects demonstrated for plasma lactate concentration (Table 4). The PG-treated ewes demonstrated a greater mean plasma lactate concentration compared with the CTL $(P<0.001)$ and the GLY $(P$ $<0.001)$ groups. The CTL and GLY groups demonstrated similar mean plasma lactate concentration $(P$ $=0.11$ ). No significant interaction between treatment and time for the lactate concentration was detected for $12 \mathrm{~h}$ after drenching $(P=0.66)$. There was no difference between groups for plasma lactate concentration before the treatments $(P=0.30)$. The plasma lactate concentration of the PG group increased within $1 \mathrm{~h}$ after treatment, and it was 2.8-fold greater than that of the CTL group $(P=0.001)$ and tended to be greater (1.8-fold) than that of the GLY group $(P=0.06 ; 1.88$ $\pm 0.15,0.68 \pm 0.16$, and $1.06 \pm 0.15 \mathrm{mmol} / \mathrm{L}$, respectively). The lactate concentration in the PG ewes remained greater than in both other groups at $2,3,4,5$, $6,7,8,9$, and $10 \mathrm{~h}$ after drenching $(P=0.05)$.

\section{Plasma Total Glycerol Concentration}

We suspect that the results we observed in the plasma total glycerol (TG) concentration might result from an artifact of the analysis, because the kit we used (TRIGL, Roche Holding GmbH), as well as the one Osman et al. (2008) used (T7532-120, Pointe Scientific Inc.), determined the glycerol concentration in the plasma after hydrolysis of TG. Therefore, we refer to these data as reflecting the glycerol concentration in plasma of the ewes, which include both the absorbed drenched glycerol and glycerol after hydrolysis of TG. There was an overall treatment effect $(P=0.01)$ and an overall time effect $(P<0.001)$ for TG concentration (Table 4). Significant interaction between treatment and time for plasma TG concentration for $12 \mathrm{~h}$ after drenching was also detected $(P<0.001$; Table 4$)$. The plasma TG concentration for all groups of ewes during the $12 \mathrm{~h}$ is presented in Figure 1E. The basal TG concentration was $26 \pm 2.7 \mathrm{mg} / \mathrm{dL}$ and reached a peak of $201.1 \pm 31.4 \mathrm{mg} / \mathrm{dL}$ within $2 \mathrm{~h}$ after drenching in the GLY ewes, which was $\sim 8$-fold greater than in the CLT and PG ewes $(P=0.02)$. The TG concentration in the GLY group began to decline from $2 \mathrm{~h}$ after drenching, remained significantly greater than the CTL group until $4 \mathrm{~h}(P=0.02)$, and reached similar concentration to the PG and CTL groups from $5 \mathrm{~h}$ after drenching until the conclusion at $12 \mathrm{~h}$.

\section{Plasma Insulin Concentration}

The treatment effect for plasma insulin concentration tended to be significant $(P=0.07$; Table 4$)$. A time effect $(P=0.001)$ and a treatment $\times$ time effect $(P<$ 0.001 ) were demonstrated for plasma insulin concentration. The plasma insulin concentration tended to be higher in the GLY than in the CTL ewes $(43 \%, P=$ $0.07)$, but was similar to that of the PG ewes $(P=$ $0.12)$. The insulin concentration over time is presented in Figure 1F. The basal insulin blood concentration for all ewes was $40 \pm 5.5 \mu \mathrm{IU} / \mathrm{mL}$, with no difference between groups $(P=0.75)$. Treating ewes with GLY caused a greater plasma insulin concentration at 2,3 , 4 , and $5 \mathrm{~h}$ after drenching compared with the PG and CTL groups $(P<0.05)$. The plasma insulin concentra- 
tion of the GLY group was the same as the PG and CTL groups from 6 to $12 \mathrm{~h}$ after drenching.

\section{LDH and AST Plasma Concentration}

The plasma LDH activity for $12 \mathrm{~h}$ after drenching was not different among groups $(P=0.3$; Table 4$)$. In addition, no effect of time $(P=0.78)$ or interaction between treatment and time $(P=0.27)$ for plasma $\mathrm{LDH}$ concentration was detected. There was no treatment $(P$ $=0.15)$, time $(P=0.68)$ or treatment $\times$ time interaction $(P=0.40)$ for plasma AST concentration (Table 4). Furthermore, the changes in LDH and AST activity over time were negligible (data are not shown).

\section{DISCUSSION}

In this study, we examined the short-term effects of drenching PG or GLY on late-pregnant prolific AfecAssaf ewes and found that during the first $5 \mathrm{~h}$ after drenching, the PG was mainly effective in reducing the $\mathrm{BHB}$, where the effects of GLY were more prominent in increasing the glucose plasma concentration. We also found that plasma lactate concentration greatly increased as compared with PG administration. We assume that the PG was metabolized mainly in the liver into lactate (Ruddick, 1972), and then converted to pyruvate, and finally to OAA, which apparently integrates into the Krebs cycle and decreases the production of ketone bodies, rather than increases the glucose production through the gluconeogenesis pathway (Figure 2).

\section{Effects on Plasma Glucose Concentration}

The plasma glucose concentration was increased in the first $5 \mathrm{~h}$ after drenching in the GLY ewes but not in the PG ewes. However, the glucose concentration in the PG ewes was enhanced during 7 to $12 \mathrm{~h}$ after drenching. Propylene glycol is metabolized in the rumen to propionate, propanol, and propanal, or absorbed intact from the rumen and then metabolized in the liver to lactate (Ruddick, 1972; Kristensen and Raun, 2007), which later is converted to pyruvate by LDH (Emery et al., 1967; Nielsen and Ingvartsen, 2004; Kristensen and Raun, 2007). Pyruvate is directly metabolized to OAA, whereas propionate can be metabolized downstream to OAA. Without previous adaptation, as in our study, it is more likely that PG will mainly be absorbed intact from the rumen at the rate of $40 \%$ per hour and with a half-life of $3 \mathrm{~h}$, as was shown by Herdt and Emery (1992). Previous reports demonstrated the inconclusive glucogenic effects of PG administration on ruminants.
Drenching ewes (Ferraro et al., 2016) and dairy cows (Miyoshi et al., 2001) or the infusion of PG into the rumen (Piantoni and Allen, 2015) increased blood glucose concentration 30 to 90 min after treatment. Christensen et al. (1997) reported a tendency of increased plasma glucose concentration in dairy cows after drenching with PG. However, Kristensen et al. (2002) reported that glucose concentration did not increase in response to the intraruminal infusion of labeled PG in lactating cows. In the present study, we did not observe an increase in glucose concentration in the very short-term (1-5 h) with PG drenching; however, we observed a moderate increase from $6 \mathrm{~h}$ onward. The discrepancy between studies investigating the effect of PG supplementation on glucose concentration can be explained by the metabolic status of the animals (Maurer et al., 2017), and the product quality and formation.

Glycerol can also be absorbed intact or metabolized in the rumen. When GLY is absorbed intact, it can be metabolized to glucose predominately in the liver, where it is metabolized to glycerol-3-phosphate and dihydroxyacetone phosphate (Goff and Horst, 2003; Figure 2). This is the shorter pathway of the gluconeogenesis process that does not pass through OAA (Johnson, 1954), which may be the case in our study (Figure 2). The sharp increase in the plasma TG concentration in the GLY ewes, which we assume originated mainly from the supplemented glycerol, supports this suggested pathway in our study. Other in vitro and in vivo studies revealed that GLY is primarily absorbed intact without alteration from the rumen (Ferraro et al., 2009, 2016; Werner Omazic et al., 2015). However, in vitro experiments using rumen fluid demonstrated that GLY metabolizes primarily to butyrate and in a small portion to propionate, and that it reduces acetate formation (Ferraro et al., 2009, 2016), which is probably in contrast with our findings. Wright (1969) reported in an in vitro study that acetate is the main VFA produced upon GLY fermentation in rumen fluid. Nevertheless, other reports, in an in vitro study using rumen contents obtained from sheep (Garton et al., 1961) or in an in vivo study in transition cows (Defrain et al., 2004), found that GLY is metabolized mainly to propionate. Piantoni and Allen, (2015) also suggested that in dairy cows, when GLY infused to the reticulorumen it is likely mostly metabolized to acetic acid. The difference between studies is probably due to rumen microbial populations as suggested by Wright (1969), or the rumen environment. The results of the present study are in agreement with other reports, in which GLY increased the blood glucose concentration 30 to $180 \mathrm{~min}$ after drenching $1 \mathrm{~kg}$ of glycerol solution mixed with $1 \mathrm{~L}$ of water to transition cows (Linke 
and Hippen, 2005) or ruminal infusion of $300 \mathrm{~mL}$ of GLY in Piantoni and Allen, 2015. In another study, Defrain et al. (2004) tested 2 doses of GLY, 0.43 and $0.86 \mathrm{~kg} / \mathrm{d}$, added to the TMR as top-dressing in transition cows and did not observe an increase in glucose concentration in both doses. Our results indicate that GLY is probably absorbed intact, which was also found in several reports (Ferraro et al., 2009, 2016; Werner Omazic et al., 2015), and that it is partly metabolized to glucose in the liver through the short pathway in the gluconeogenesis process (Figure 2). It should be also mentioned that it was found in monogastric animals that the liver is responsible for at least three-fourths of the GLY metabolism, the kidney is responsible for up to one-fourth, and brain, intestine, muscle, and lungs also use GLY (Tao et al., 1983).

\section{Effects on Plasma BHB Concentration}

The plasma BHB concentration decreased within $1 \mathrm{~h}$ in response to $\mathrm{PG}$ and GLY administration and remained less until $5 \mathrm{~h}$ after drenching as compared with CTL ewes. Many other previous reports documented a decrease in $\mathrm{BHB}$ concentration in response to PG administration (Grummer et al., 1994; Nielsen and Ingvartsen, 2004; Piantoni and Allen, 2015), which was accompanied by elevated blood glucose levels. Propylene glycol can be metabolized in the mitochon-

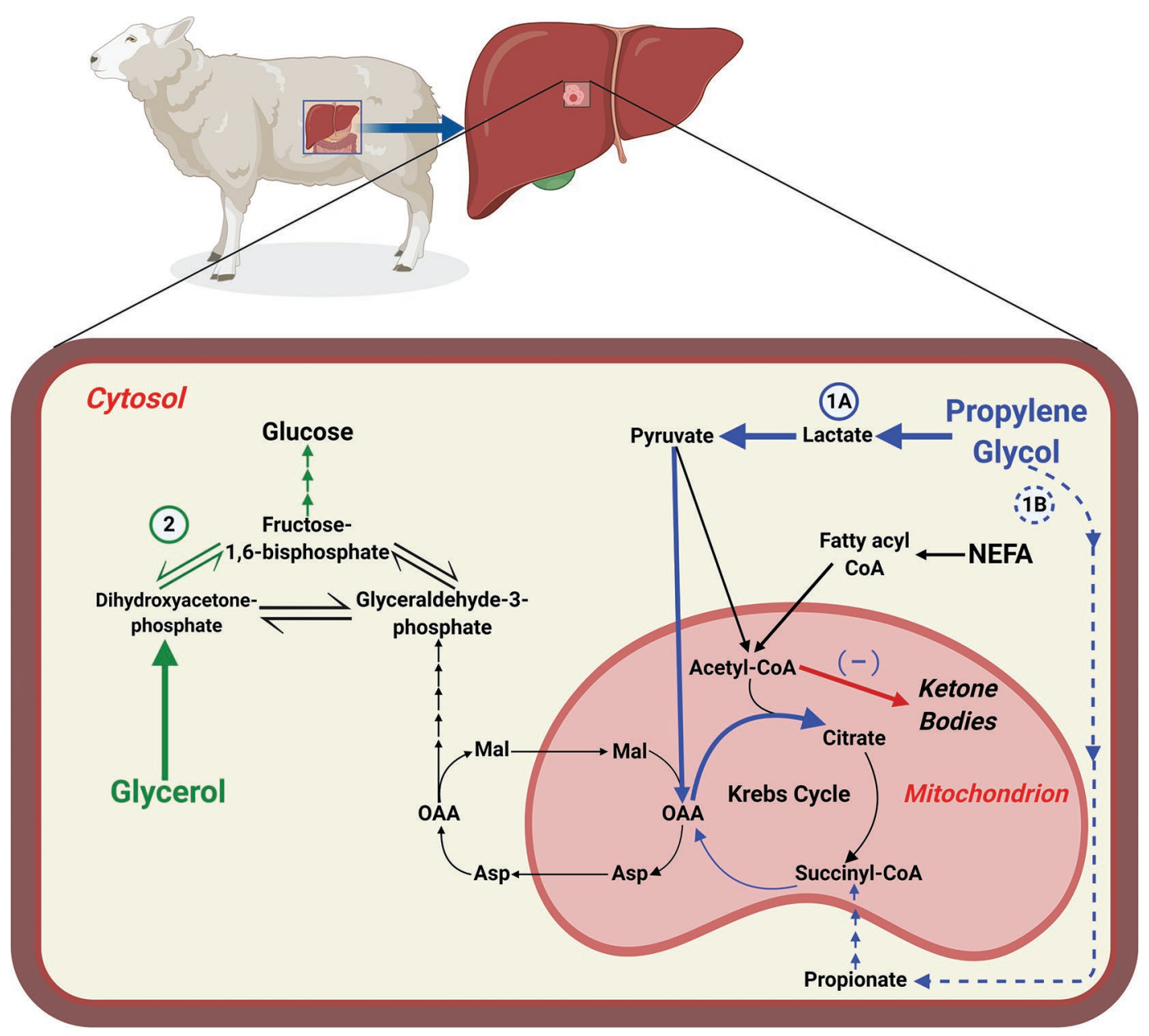

Figure 2. Metabolism of propylene glycol (PG) and glycerol (GLY) in gluconeogenesis and related metabolic cycles. The PG affected the glucogenic status of the animal by 2 primary pathways: PG is absorbed intact (1A, solid blue line) and metabolizes in the liver to lactate, then converts to pyruvate and finally to oxaloacetate (OAA), which integrates into the Krebs cycle (Kristensen and Raun, 2007); or PG fermented in the rumen, primarily to propionic acid (1B, dashed blue line), which converts in the liver mitochondria to succinyl-CoA and integrates into the Krebs cycle (Nielsen and Ingvartsen, 2004). In contrast, GLY absorbed intact reaches the liver and integrates into the cytosolic gluconeogenesis (2, solid green line), or partially ferments in the rumen to butyric acid. We assume that in the present study, the PG was mainly metabolized through pathway $1 \mathrm{~A}$, which eventually decreased the BHB, whereas the GLY was metabolized through pathway 2 , which increased the glucose production. NEFA = nonesterified fatty acids. 
dria to OAA through succinyl-CoA, which accelerates the oxidation of acetyl-CoA in the Krebs cycle, and its removal from the ketogenesis pathway (Nielsen and Ingvartsen, 2004; Piantoni and Allen, 2015). From the findings of the present study, we can speculate that the main part of the OAA, produced in response to PG drenching, was transferred to the Krebs cycle to reduce the BHB production and that only a small portion continued upstream in the gluconeogenesis process to produce glucose (Figure 2). This can explain the decrease in BHB concentration and the negligible increase in glucose concentration in the short term after PG drenching in late-pregnant ewes.

In the present study, the plasma BHB concentration was less in the GLY compared with the CTL ewes; however, Linke and Hippen (2005) and Defrain et al. (2004) reported an increase in BHB concentration in cows drenched or fed glycerol. This is most probably because of the increase in the rumen butyric acid in response to GLY supplementation and following conversion to BHB through the rumen wall (Hippen et al., 2008). In contrast, Piantoni and Allen (2015) observed a reduction in mean BHB concentration after an infusion of $600 \mathrm{~mL}$ of GLY to the reticulorumen, which is similar to our findings.

\section{Effects on Plasma NEFA Concentration}

Plasma NEFA concentration decreased within $1 \mathrm{~h}$ in response to PG and GLY administration as compared with those of the CTL ewes and was significantly less until $4 \mathrm{~h}$ after drenching in the PG ewes and until 8 $\mathrm{h}$ in the PG ewes. In all groups, the plasma NEFA concentration was lower from 5 to 12 than from 0 to 4 $\mathrm{h}$ relative to drenching. The decrease in plasma NEFA concentration from $3 \mathrm{~h}$ and later in the CTL ewes in the present study is presumably due to the postfeeding increase in glucose concentration, which led to elevated blood insulin. Insulin is a lipogenic hormone that leads to NEFA clearance from the bloodstream (Duncan et al., 2007). The decrease in plasma NEFA concentration in response to PG administration was reported previously in several studies (Grummer et al., 1994; Piantoni and Allen, 2015). In contrast to our findings, in those studies, the decrease in NEFA was accompanied by an increase in glucose and insulin concentration. However, in Cozzi et al. (1996), adding 200 or $400 \mathrm{~g}$ of PG/d to the TMR of mid-lactation cows did not affect plasma NEFA concentration. It has been established that mixing PG in TMR or an oral drench has a different effect on blood metabolites. Christensen et al. (1997) reported that mixing PG in the TMR is much less effective than drenching; this is probably due to the slow consumption of PG during the day (Linke and Hippen,
2005). It was also suggested that the NEFA baseline concentration affects the NEFA reduction effectiveness by PG (Nielsen and Ingvartsen, 2004).

Propylene glycol reduces NEFA concentration without increasing blood glucose and insulin, probably by 2 main pathways. First, PG downstream of metabolites induces the Krebs cycle, which will increase the oxidation of acetyl-CoA (Nielsen and Ingvartsen, 2004). When acetyl-CoA oxidation is more efficient, it can increase NEFA clearance by the liver from the bloodstream. In the second pathway, PG is metabolized to lactate in the liver; lactate is a mediator in the lipotropic action of insulin (Liu et al., 2009; Ahmed et al., 2010). It is possible that in the present study, the extremely elevated lactate levels in the PG ewes directly reduced the lipolysis in the adipose tissues.

In agreement with the present study results, it was reported that orally administering $1 \mathrm{~kg}$ of $80.2 \%$ GLY solution to mild ketosis lactating cows decreased NEFA concentration and increased glucose and insulin concentration (Linke and Hippen, 2005). In addition, infusion of 300 and $600 \mathrm{~mL}$ of $99.5 \%$ pure GLY to the reticulorumen also decreased lipolysis as glucose and insulin concentration increased (Piantoni and Allen, 2015). In contrast, a top-dressing of $430 \mathrm{~g}$ of $80.2 \%$ GLY solution to transition cows was not effective in decreasing the NEFA concentration (Omazic, 2013).

\section{Effects on Plasma Lactate Concentration}

In the current study, drenching PG dramatically increased the plasma lactate concentration, whereas no marked changes were recorded in the CTL or GLY ewes. The effect of time was not significant for lactate, but this is mainly because there was a sharp increase in plasma lactate concentration in the PG group within 1 $\mathrm{h}$, which remained constant until $5 \mathrm{~h}$ after drenching. Propylene glycol can be metabolized in the liver to lactate by alcohol and aldehyde dehydrogenase (Emery et al., 1967; Kristensen et al., 2002). It has been reported that an infusion of $650 \mathrm{~g}$ of $\mathrm{PG}$ to the rumen of milking cows increased plasma lactate, and it was concluded by the authors that PG is primarily metabolized to lactate in the liver (Kristensen and Raun, 2007). In addition, a recent study reported that intravenous injection of $\mathrm{PG}$ into the jugular vein of nonpregnant ewe lambs sharply increased the lactate concentration (Kalyesubula et al., 2019). These reports are in agreement with our results, in which a dramatic increase in plasma lactate concentration was observed in response to PG drenching. The higher plasma lactate concentration remained high in the ewes from 1 to $12 \mathrm{~h}$ after drenching. Lactate has adverse effects, and lactate accumulation in the brain can cause neuronal disorders, ataxia, and depression 
(Christopher et al., 1990; Abeysekara et al., 2007). It was also reported in humans that intravenous injection of PG caused metabolic acidosis (Zosel et al., 2010).

However, no changes in lactate concentration over time were observed in the CTL and GLY ewes in response to PG administration, and to the best of our knowledge, no other studies reported any changes in blood lactate concentration as a result of GLY treatment.

\section{Effects on Plasma Total Glycerol Concentration}

The plasma TG concentration increased dramatically after drenching with GLY, whereas CTL and PG treatments did not affect TG concentration after drenching. The TG concentration was higher in the GLY group until $5 \mathrm{~h}$ after drenching but returned to basal levels at $6 \mathrm{~h}$ after drenching. Therefore, the dramatic increase in the GLY ewes immediately after drenching indicates that this sharp increase originated from the exogenous drenched glycerol. The increase in TG in the GLY ewes was accompanied by increased glucose and insulin and decreased NEFA and BHB concentration. We assume that rapid absorbance of GLY takes place in the rumen, and the results of the present study support the wellestablished finding that GLY can be absorbed from the rumen intact (Trabue et al., 2007; Ferraro et al., 2009, 2016).

\section{Effects on Plasma Insulin Concentration}

The plasma insulin concentration was increased in the first $5 \mathrm{~h}$ after drenching in the GLY, but not in the PG ewes. However, the insulin concentration in the PG ewes was increased postfeeding and was similar to GLY ewes from 5 to $12 \mathrm{~h}$ after drenching. In agreement with the present results, Linke and Hippen, (2005) observed a significant increase in insulin concentration after drenching $1 \mathrm{~L}$ of GLY to lactating cows. In contrast, Piantoni and Allen (2015) did not observe an increase in the insulin concentration when they infused $300 \mathrm{~mL}$ of GLY to the reticulo-rumen of transition milking cows; however, an infusion of $600 \mathrm{~mL}$ of GLY caused an insignificant increase in the insulin for $1 \mathrm{~h}$. The increase in the insulin concentration in GLY ewes can be a consequence of an increased glucose concentration as a result of GLY metabolism in the liver (Johnson, 1954) or as a result of propionate production in the rumen as a consequence of GLY fermentation. It is more likely that the increased glucose concentration is the main reason for the elevated insulin concentration rather than the propionate concentration, because it has been reported that GLY is slowly metabolized in the rumen of sheep, and that only a small portion is metabolized to propionate (Ferraro et al., 2009, 2016).

Drenching sheep (Ferraro et al., 2016), pregnant heifers (Christensen et al., 1997), or milking cows (Miyoshi et al., 2001) with PG or infusing PG into the rumen of milking cows (Piantoni and Allen, 2015) increased insulin plasma concentration. However, in the present study, we did not observe any effect of PG on plasma insulin concentration. Similarly, Kristensen et al. (2002) also did not observe an increase in insulin concentration when they infused $30 \mathrm{~L}$ of $500 \mathrm{mmol} / \mathrm{L}$ of PG solution into the washed rumen of low-producing lactating cows. Studer et al. (1993) suggested that PG may have a direct secretagogue effect on insulin; however, the results of the current study and those of Kristensen et al. (2002) do not support this suggestion.

\section{Effects on Plasma AST and LDH Activity}

The LDH and AST activity in the plasma was not affected after drenching with PG or GLY. Both LDH and AST activity in the present study were within the normal range in sheep (Pugh and Baird, 2012). In agreement with the present study results, Nazifi et al. (2005) did not observe any changes in AST and LDH diurnal activity in sheep. It has also been reported that adding GLY or PG to dairy cows' TMR (Adamski et a., 2011) or drenching dry and fresh cows with PG (Maurer et al., 2017) does not affect AST activity.

\section{CONCLUSIONS}

Monitoring the short-term effects of late-pregnant prolific ewes drenched with PG or GLY revealed that during the first $5 \mathrm{~h}$ after drenching the $\mathrm{PG}$ was mainly effective in reducing the BHB, where the effect of GLY was more prominent in increasing the glucose plasma concentration. We also found that the plasma lactate concentration greatly increased in response to $\mathrm{PG}$, but not to GLY administration. Therefore, we assume that the entry point to gluconeogenesis is different between these 2 substances; PG is metabolized in the liver and finally integrated into the Krebs cycle to decrease the production of ketone bodies, whereas the GLY was metabolized to glucose predominately in the liver, via the cytosolic gluconeogenesis shorter pathway, to produce glucose rather than OAA (Figure 2). The different after drenching fluctuations in blood metabolites between PG and GLY revealed that timing is a crucial factor in determining the effectiveness of these supplements. In addition, the beneficial effects of drenching pregnant ewes with PG or GLY was only for a short time $(12 \mathrm{~h})$, which means that continuous treatment is 
required to avoid the development of hypoglycemia or hyperketonemia in such ewes. The results of the present study revealed that the short-term effects of common glucogenic precursors such as PG and GLY are not entirely known and that further research is essential to elucidate the short- and long-term effects of glucogenic precursor supplementation and to determine the proper dosage required for treating prolific ewes.

\section{ACKNOWLEDGMENTS}

The authors thank the entire staff of the experimental flock at the Volcani Center, Rishon LeZion, Israel, for their assistance with animal care. The authors have not stated any conflicts of interest.

\section{REFERENCES}

Abeysekara, S., J. M. Naylor, A. W. A. Wassef, U. Isak, and G. A. Zello. 2007. D-Lactic acid-induced neurotoxicity in a calf model. Am. J. Physiol. Endocrinol. Metab. 293:E558-E565. https://doi .org/10.1152/ajpendo.00063.2007.

Adamski, M., R. Kupczyński, G. Chladek, and D. Falta. 2011. Influence of propylene glycol and glycerin in Simmental cows in periparturient period on milk yield and metabolic changes. Arch. Anim. Breed. 54:238-248. https://doi.org/10.5194/aab-54-238-2011.

Ahmed, K., S. Tunaru, C. Tang, M. Müller, A. Gille, A. Sassmann, J. Hanson, and S. Offermanns. 2010. An autocrine lactate loop mediates insulin-dependent inhibition of lipolysis through GPR81. Cell Metab. 11:311-319. https://doi.org/10.1016/j.cmet.2010.02.012.

Cal-Pereyra, L., J. Acosta-Dibarrat, A. Benech, S. Da Silva, A. Martín, and J. Ramiro González-Montańa. 2012. Ewe pregnancy toxemia: Revision. Rev. Mex. Cienc. Pecu. 3:247-264.

Christensen, J. O., R. R. Grummer, F. E. Rasmussen, and S. J. Bertics. 1997. Effect of method of delivery of propylene glycol on plasma metabolites of feed-restricted cattle. J. Dairy Sci. 80:563-568. https://doi.org/10.3168/jds.S0022-0302(97)75971-X.

Christopher, M. M., J. H. Eckfeldt, and J. W. Eaton. 1990. Propylene glycol ingestion causes D-lactic acidosis. Lab. Invest. 62:114-118.

Cozzi, G., P. Berzaghi, F. Gottordo, G. Gabai, and I. Andrighetto. 1996. Effects of feeding propylene glycol to mid-lactating dairy cows. Anim. Feed Sci. Technol. 64:43-51.

DeFrain, J. M., A. R. Hippen, K. F. Kalscheur, and P. W. Jardon. 2004. Feeding glycerol to transition dairy cows: Effects on blood metabolites and lactation performance. J. Dairy Sci. 87:4195-4206. https://doi.org/10.3168/jds.S0022-0302(04)73564-X.

Drackley, J. K. 1999. Biology of dairy cows during the transition period: The final frontier? J. Dairy Sci. 82:2259-2273. https://doi .org/10.3168/jds.S0022-0302(99)75474-3.

Duncan, R. E., M. Ahmadian, K. Jaworski, E. Sarkadi-Nagy, and H. S. Sul. 2007. Regulation of lipolysis in adipocytes. Annu. Rev. Nutr. 27:79-101. https://doi.org/10.1146/annurev.nutr.27.061406 .093734 .

Emery, R. S., R. E. Brown, and A. L. Black. 1967. Metabolism of DL-1,2-propanediol-2- ${ }^{14} \mathrm{C}$ in a lactating cow. J. Nutr. 92:348-356. https://doi.org/10.1093/jn/92.3.348.

Ferraro, S. M., G. D. Mendoza, L. A. Miranda, and C. G. Gutiérrez. 2009. In vitro gas production and ruminal fermentation of glycerol, propylene glycol and molasses. Anim. Feed Sci. Technol. 154:112118. https://doi.org/10.1016/j.anifeedsci.2009.07.009.

Ferraro, S. M., G. D. Mendoza, L. A. Miranda, and C. G. Gutiérrez. 2016. In vitro ruminal fermentation of glycerol, propylene glycol and molasses combined with forages and their effect on glucose and insulin blood plasma concentrations after an oral drench in sheep. Anim. Feed Sci. Technol. 213:74-80. https://doi.org/10 .1016/j.anifeedsci.2016.01.010.
Garton, G. A., A. K. Lough, and E. Vioque. 1961. Glyceride hydrolysis and glycerol fermentation by sheep rumen contents. J. gen. J. Gen. Microbiol. 25:215-225.

Goff, J. P., and R. L. Horst. 2003. Oral glycerol as a gluconeogenic precursor in the treatment of ketosis and fatty liver. Acta Vet. Scand. 44(Suppl 1):P40. https://doi.org/10.1186/1751-0147-44-S1-P40.

Gootwine, E., S. Reicher, and A. Rozov. 2008. Prolificacy and lamb survival at birth in Awassi and Assaf sheep carrying the FecB (Booroola) mutation. Anim. Reprod. Sci. 108:402-411. https://doi .org/10.1016/j.anireprosci.2007.09.009.

Grummer, R. R., J. C. Winkler, S. J. Bertics, and V. A. Studer. 1994. Effect of propylene glycol dosage during feed restriction on metabolites in blood of prepartum holstein heifers. J. Dairy Sci. 77:36183623. https://doi.org/10.3168/jds.S0022-0302(94)77306-9.

Hay, W. W. Jr., J. W. Sparks, R. B. Wilkening, F. C. Battaglia, and G. Meschia. 1983. Partition of maternal glucose production between conceptus and maternal tissues in sheep. Am. J. Physiol. 245:E347-E350. https://doi.org/10.1152/ajpendo.1983.245.4 .E347.

Herdt, T. H., and R. S. Emery. 1992. Therapy of diseases of ruminant intermediary metabolism. Vet. Clin. North Am. Food Anim. Pract. 8:91-106. https://doi.org/10.1016/S0749-0720(15)30761-1.

Hippen, A. R., J. M. Defrain, and P. L. Linke. 2008. Glycerol and Other Energy Sources for Metabolism and Production of Transition Dairy Cows. Florida Ruminant Nutrition Symposium, Gainesville. Department of Animal Science, University of Florida, Gainesville.

Jefferies, B. 1961. Body condition scoring and its use in management. Tasman. J. Agric. 32:19-21.

Johnson, R. B. 1954. The treatment of ketosis with glycerol and propylene glycol. Cornell Vet. 44:6-21.

Kalyesubula, M., A. Rosov, T. Alon, U. Moallem, and H. Dvir. 2019. Intravenous infusions of glycerol versus propylene glycol for the regulation of negative energy balance in sheep: A randomized trial. Animals 9:731. https://doi.org/10.3390/ani9100731.

Kristensen, N. B., A. Danfaer, B. A. Røjen, B. M. L. Raun, M. R. Weisbjerg, and T. Hvelplund. 2002. Metabolism of propionate and 1,2-propanediol absorbed from the washed reticulorumen of lactating cows. J. Anim. Sci. 80:2168-2175. https://doi.org/10.2527/ 2002.8082168x.

Kristensen, N. B., and B. M. L. Raun. 2007. Ruminal and intermediary metabolism of propylene glycol in lactating Holstein cows. J. Dairy Sci. 90:4707-4717. https://doi.org/10.3168/jds.2007-0295.

Linke, P. L., and A. R. Hippen. 2005. Ruminal and plasma responses in dairy cows to drenching or feeding glycerol. J. Undergrad. Res. 3:49-60.

Liu, C., J. Wu, J. Zhu, C. Kuei, J. Yu, J. Shelton, S. W. Sutton, X. Li, S. J. Yun, T. Mirzadegan, C. Mazur, F. Kamme, and T. W. Lovenberg. 2009. Lactate inhibits lipolysis in fat cells through activation of an orphan G-protein-coupled receptor, GPR81. J. Biol. Chem. 284:2811-2822. https://doi.org/10.1074/jbc.M806409200.

Maurer, M., W. Peinhopf, J. Gottschalk, A. Einspanier, G. Koeller, and T. Wittek. 2017. Effects of different dosages of propylene glycol in dry cows and cows in early lactation. J. Dairy Res. 84:375384. https://doi.org/10.1017/S0022029917000486.

Miyoshi, S., J. L. Pate, and D. L. Palmquist. 2001. Effects of propylene glycol drenching on energy balance, plasma glucose, plasma insulin, ovarian function and conception in dairy cows. Anim. Reprod. Sci. 68:29-43. https://doi.org/10.1016/S0378-4320(01)00137-3.

Moallem, U., A. Rozov, E. Gootwine, and H. Honig. 2012. Plasma concentrations of key metabolites and insulin in late-pregnant ewes carrying 1 to 5 fetuses. J. Anim. Sci. 90:318-324. https://doi.org/ 10.2527/jas.2011-3905.

Nazifi, S., M. Saeb, T. Karimi, and S. Ghanbari. 2005. Diurnal variation of serum biochemical parameters in the Iranian fat-tailed sheep. Comp. Clin. Pathol. 14:1-4. https://doi.org/10.1007/ s00580-005-0538-6.

Nielsen, N. I., and K. L. Ingvartsen. 2004. Propylene glycol for dairy cows: A review of the metabolism of propylene glycol and its effects on physiological parameters, feed intake, milk production and risk of ketosis. Anim. Feed Sci. Technol. 115:191-213. https://doi .org/10.1016/j.anifeedsci.2004.03.008. 
Omazic, A. W. 2013. Glycerol supplementation in dairy cows and calves. PhD Diss. Swedish University of Agricultural Sciences, Uppsala, Sweden.

Osman, M. A., P. S. Allen, N. A. Mehyar, G. Bobe, J. F. Coetzee, K. J. Koehler, and D. C. Beitz. 2008. Acute metabolic responses of postpartal dairy cows to subcutaneous glucagon injections, oral glycerol, or both. J. Dairy Sci. 91:3311-3322. https://doi.org/10 .3168/jds.2008-0997.

Piantoni, P., and M. S. Allen. 2015. Evaluation of propylene glycol and glycerol infusions as treatments for ketosis in dairy cows. J. Dairy Sci. 98:5429-5439. https://doi.org/10.3168/jds.2015-9476.

Pugh, D. G., and A. N. Baird. 2012. Sheep and Goat Medicine. 2nd ed. Saunders, Maryland Heights, MO.

Ruddick, J. A. 1972. Toxicology, metabolism, and biochemistry of 1,2-propanediol. Toxicol. Appl. Pharmacol. 21:102-111. https:// doi.org/10.1016/0041-008X(72)90032-4.

Sargison, N. D. 2007. Pregnancy toxaemia. Pages 359-363 in Diseases of Sheep. 4th ed. I. D. Aitken, ed. Blackwell Publishing, Edinburgh, UK

Scott, P. R., N. D. Sargison, C. D. Penny, R. S. Pirie, and J. M. Kelly 1995. Cerebrospinal fluid and plasma glucose concentrations of ovine pregnancy toxaemia cases, inappetant ewes and normal ewes during late gestation. Br. Vet. J. 151:39-44. https://doi.org/10 .1016/S0007-1935(05)80063-6.

Studer, V. A., R. R. Grummer, S. J. Bertics, and C. K. Reynolds. 1993. Effect of prepartum propylene glycol administration on periparturient fatty liver in dairy cows. J. Dairy Sci. 76:2931-2939. https://doi.org/10.3168/jds.S0022-0302(93)77633-X.

Tao, R. C., R. E. Kelley, N. N. Yoshimura, and F. Benjamin. 1983 Glycerol: Its metabolism and use as an intravenous energy source. J. Paren. Enter. Nutr. 7:470-88.
Trabue, S., K. Scoggin, S. Tjandrakusuma, M. A. Rasmussen, and P. J. Reilly. 2007. Ruminal fermentation of propylene glycol and glycerol. J. Agric. Food Chem. 55:7043-7051. https://doi.org/10 .1021/jf071076i.

Twardock, A. R., H. W. Symonds, B. F. Sansom, and G. J. Rowlands. 1973. The effect of litter size upon foetal growth rate and the placental transfer of calcium and phosphorus in superovulated Scottish half-bred ewes. Br. J. Nutr. 29:437-446. https://doi.org/ 10.1079/BJN19730119.

Werner Omazic, A., C. Kronqvist, L. Zhongyan, H. Martens, and K. Holtenius. 2015. The fate of glycerol entering the rumen of dairy cows and sheep. J. Anim. Physiol. Anim. Nutr. (Berl.) 99:258-264. https://doi.org/10.1111/jpn.12245.

Wright, D. E. 1969. Fermentation of glycerol by rumen micro-organisms. N. Z. J. Agric. Res. 12:281-286. https://doi.org/10.1080/ 00288233.1969 .10421180$.

Wu, G., F. W. Bazer, J. M. Wallace, and T. E. Spencer. 2006. Boardinvited review: Intrauterine growth retardation: Implications for the animal sciences. J. Anim. Sci. 84:2316-2337. https://doi.org/ $10.2527 /$ jas.2006-156.

Zamir, S., A. Rozov, and E. Gootwine. 2009. Treatment of pregnancy toxaemia in sheep with flunixin meglumine. Vet. Rec. 165:265-266. https://doi.org/10.1136/vr.165.9.265.

Zosel, A., E. Egelhoff, and K. Heard. 2010. Severe lactic acidosis after an iatrogenic propylene glycol overdose. Pharmacotherapy 30:219. https://doi.org/10.1592/phco.30.2.219. 